\title{
Towards a Framework for Learning in the OSMA Serious Game Engine
}

\author{
$\underline{\text { doi:10.3991/ijet.v5s3.1497 }}$ \\ T. Coenen, E. Cloosen, V. Van der Sluys and F. Smolders \\ PHL University College, Hasselt, Belgium
}

\begin{abstract}
Online multiplayer serious games offer a way to support learning in a gaming paradigm that is familiar to many players and has proven its effectiveness in providing sustainably enjoyable gameplay. We aim to decrease development cost for these games by providing a modular game design framework and a component-based technical architecture. The technical architecture and the game design framework will be implemented and iteratively refined through two proofs of concept.
\end{abstract}

Index Terms-Games, Learning Systems, Reconfigurable architectures

\section{INTRODUCTION}

\section{A. The OSMA-SGE project}

Serious games are becoming a powerful tool in education [1]. The interest in this technology is growing and many organizations are investing in the development of such games. When creating a new serious game, the creators often have to start anew, making game development expensive. Therefore, diminishing the development costs of serious games is a goal that both appeals to game developers as to the organizations that implement them. The objective of the OSMA-SGE project is to do this by making knowledge and technology available to SME's engaged in the creation of serious games. In order to do this, different work packages have been designed, reflecting the basic elements necessary to create serious games. These packages encompass game design, pedagogy, graphical design, sound design and development.

The project is guided by a number of stakeholders representing practitioners in the field, to ensure the practical relevance of the project. These stakeholders are Belgian SME's engaged in the creation of serious games and organizations interested in the application of serious games. In order to ground the knowledge and technologic output of the project, two demonstrators will be created. One will take place in the area of employability and another one in the area of cultural heritage. We are currently designing and implementing the employability demonstrator and will present our progress in this paper.

\section{B. Serious games}

To many people, a "serious game” is an oxymoron. Indeed, it is not easy to see how a game can be both entertaining or fun and serious or educational at the same time. It has been suggested by some that merely labeling a game as "serious" can break the fun and entertaining cachet of a game and take away the motivation of the player. Creating a game as a harmonious mix of education and entertainment is not easy to achieve. Examples of games that are too serious to enjoy, or not serious enough to learn from, abound. Still, [2] finds that serious games are living up to the challenge of combining learning and playing through digital games by:

1. Generating intrinsic motivation for the player to engage in the game.

2. Providing a responsive game environment that gives the player immediate feedback.

3. Delivering complex content that allows for ample learning opportunities.

\section{Online multiplayer serious games}

The OSMA-SGE project aims to lower the production cost of online multiplayer serious games. Such games hold much potential, because of their close resemblance to some of the current dominant game paradigms. Indeed, many popular game forms are online multiplayer, like massive multiplayer online role-playing games (MMORPG), first person shooters or real-time strategy (RTS) games.

A first reason for selecting the online multiplayer game as a basic format for the creation of serious games is to offer the player a familiar gaming environment in which to learn. Secondly, a multiplayer game offers many interesting learning opportunities, like peer review and humanto-human interactions approaching real-life interactions. Thirdly, multiplayer games have a superior ability in producing emergent game dynamics as a result of simple game rules and mechanics. As people play against each other, the simplest rule set can engender complex emergent game play between players. It has been proposed by [3] that emergent aspects in games lead to a sense of wonder and surprise and make games more enjoyable. A fourth reason for looking at multiplayer serious games is that games like World of Warcraft or Call of Duty - Modern Warfare have proven that online multiplayer games can provide a sustainably enjoyable game play that players keep coming back for. Finally, as today most serious games are single player, we believe it is worth the while from an academic point of view to investigate multiplayer serious games and how they can be different from their single player cousins.

While the multiplayer format is interesting, we do not aim to develop massive online multiplayer games, in which thousands of players can play together in one game environment. The reason for this choice is that the development and maintenance cost of such games is prohibitive to their implementation by most organizations. Still, a non-massive multiplayer format can be relatively easily deployed using modern game editors like the Unity engine, used in this project. We aim for a load of about 25 players per server. 


\section{GAME DESIGN}

\section{A. The SURM framework}

Some conceptual frameworks have been developed for serious games. However, they are either too general, like [4] or not suited for online multiplayer serious games as is the case for [5]. In order to create online multiplayer serious games, we need a framework that would match this gaming paradigm and offer enough room for customization in order to harbor a learning payload. We are aiming to construct this by using a general design framework that has proven its use by creating good game play in mainstream games, and to customize this framework to the learning objectives of serious games.

The framework we are developing, which we have called SURM (Stats, Unlockables, Rank and Mini-games), is based on the type of high-level game design that is used in MMORPG's and some first-person shooters. Each player has a certain score in a statistic category that can be improved by playing mini-games. These categories can be personal attributes like "stamina" and "stealth" in a MMORPG or "creativity" and "leadership" in a serious game focused on the labor market.

A rank can be obtained by achieving a certain amount of points on a given statistic category or a combination of categories. For example, the rank "inspirational leader" could be reached when a player has reached 70/100 in the leadership category and 60/100 in the creativity category. A rank acts as a status symbol that players will aim to attain by increasing their stats and represent goals that users seek to meet in the game.

Unlockables are items or abilities that can be obtained when a certain amount of points has been reached or when another type of game objective has been met. These unlockables give the player extra abilities and impact the game dynamics of particular mini-games. For example, a "veto" unlockable could be obtained when scoring high on leadership, allowing a player to overrule the decisions of other players in a mini-game mimicking the decisionmaking process in a company.

The elements of the SURM framework have proven their value by providing enjoyable and durable game play in numerous games. However, the games in which it is normally applied are not "serious". In order to infuse the framework with a learning dimension, the different elements have to be made more concrete to fit the learning objectives at hand. Section 0 will explain how this is done in the case of our first demonstrator, for an organization called VDAB. But first, we introduce the theoretical back-

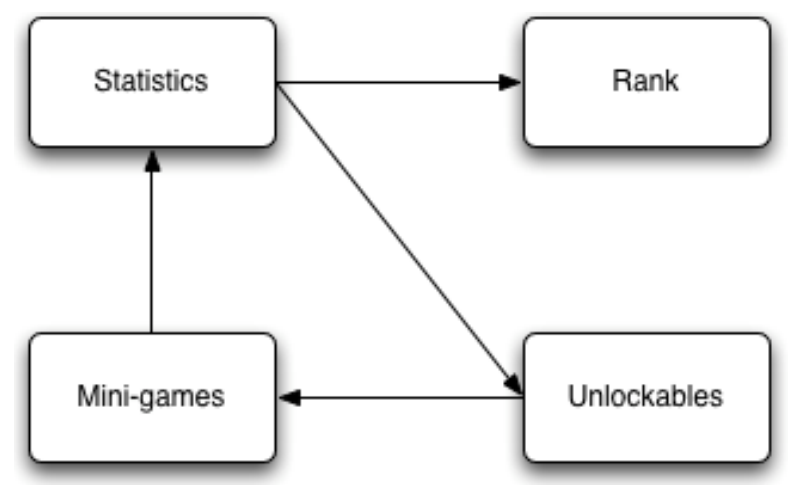

Figure 1. The SURM serious game design framework ground of the learning dimension in the multiplayer serious games we are researching.

\section{EDUCATIONAL THEORY}

This section discusses the elements of learning theory that are relevant for learning in the OSMA framework. Learning in OSMA is rooted in constructivism, is experimental, implements different forms of assessment and acknowledges the value of support from peers or a mentor.

\section{A. Constructivism}

Our research is rooted in constructivism, a learning theory that defines learning as a change in meaning constructed from prior experience [7]. The theory assumes that knowledge is individually constructed and socially co-constructed by learners, based on their interpretations of experiences in the world [8]. The constructivist assumptions of learning can be described as follows [9]:

1. All knowledge is constructed (albeit socially) and not transmitted.

2. Knowledge and meanings result from activity and are embedded in activity systems.

3. Knowledge is distributed in persons, tools, and other cultural artifacts.

4. Meaning arises out of interpretation and, thus, multiple perspectives are recognized.

5. Meaning construction is prompted by problems, questions, issues, and authentic tasks.

Critics of constructivism have formulated a number of objections. A first one is that constructivism is often seen as an all-or-nothing affair, i.e. as a complete concept covering a theory of teaching and epistemology [10]. This attempt can be considered as inconsistent with the processes of construction argued in the theory. Secondly, [11] claim that the effectiveness of constructivism is lacking and that it "almost uniformly supports direct, strong instructional guidance rather than constructivist-based minimal guidance during the instruction of novice to intermediate learners".

\section{B. Experiental learning}

According to [12], a model that successfully integrates educational theory and game design aspects does not exist. The author argues that the existing models are too artificial. As a reaction, the author created a model that links game play with experiential learning in a cyclic process through direct experience in the game world. Although the model provides valuable input for this project, the model ignores the role of social interaction in learning, which can be considered as important in the social constructivist philosophy of education [13].

Experiential Learning Theory (ELT) provides a holistic model of the learning process and a multilinear model of adult development with an emphasis on the central role of experience in the learning process [14]. ELT can be defined as "the process whereby knowledge is created through the transformation of experience. Knowledge results from the combination of grasping and transforming experience” [14]. Based on the Learning cycle [14], a conceptual basis of the process of experiential learning was created in [15], as depicted in Figure 2. 


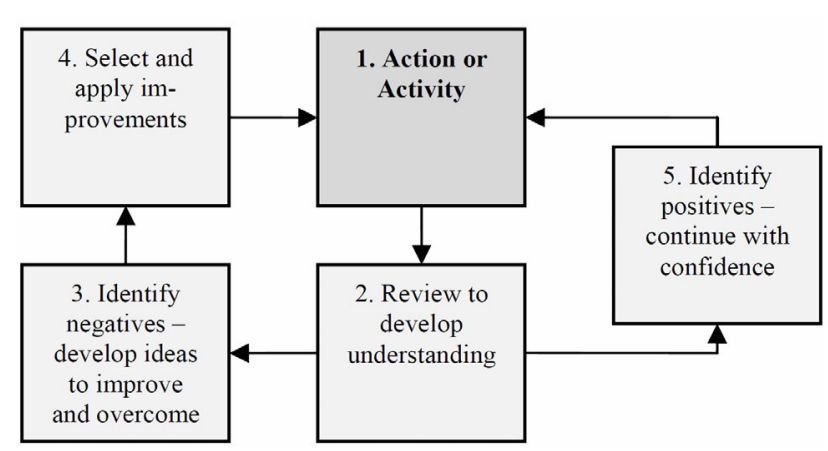

Figure 2. The process of experimental learning [15].

The cycle consists of three stages: the first is "do", the second is "review" and the third is "develop ideas for improvement”. According to [12], experiential learning provides a fruitful basis for integration of game play and pedagogy. We have therefore applied it to the development of multiplayer serious games.

\section{Assessment}

In order to determine the negatives and positives in the process of experiential learning, we use different forms of assessment. After observing the results over twenty years of peer assessment, [16] concluded that peer assessment in learning is generally a useful, reliable and valid exercise. Self-assessment is also important because people can only learn if they understand the learning goal and can assess what they need to do to meet it [17]. Both forms are complementary and are being applied in the OSMA-SGE research project.

\section{The Zone of Proximal Development}

Another influence to our research is [18], describing the Zone of Proximal Development as referring to the distance between what a learner can do without help and what he can do with help. The author defines this zone as "the distance between the actual developmental level as determined by independent problem solving and the level of potential development as determined through problem solving under adult guidance or in collaboration with more capable peers". As the serious games we are developing are multiplayer, many opportunities exist where players with different skill levels can learn from each other.

\section{THE OSMA-SGE GENERIC FEEDBACK MECHANISM}

Feedback is provided during the mini-game sessions, during which a mini-game is played three times. After each mini-game, automatic feedback is provided by the system on certain automatically measurable statistics. On other statistics, feedback is given by peers. This usage of peer-evaluation is only possible in multiplayer serious games and allows an interesting application of constructivism, ELT and the Zone of proximal development theory.

The way in which this feedback mechanism functions in the context of a specific mini-game will be clarified in the next section, in which we will discuss the first of our two proof-of-concepts, conducted at a Flemish organization called VDAB. In addition, we will indicate how the above concepts from education theory are applied in the multiplayer serious game we are developing.

\section{PROOF OF CONCEPT}

\section{A. $V D A B$}

VDAB is a Flemish public employment service offering training courses, career and job guidance. One of the services offered by this organization, is to provide assistance to jobseeker in improving their employability. VDAB is continuously looking for new ways to do this and is currently investigating the Persoonlijk ontwikkelingsplan or Personal development plan (PDP). The PDP is a way for people to gauge their own skills, weigh them against the needs of the labor market and take appropriate action to increase their employability. The essence that VDAB wishes to convey to its clients through this project is the process of the PDP, which is iterative and involves

\section{Personal introspection}

\section{Labor market insight}

3.Actions to improve personal skills, knowledge and attitude.

Introspection is needed for the person to reflect on her knowledge, skills and attitudes. These should be compared with data resulting from insight in the labor market. This labor market insight requires a general overview of the market and is not always something that a person can produce. It is typically something which a government organization like VDAB can supply, because of its ongoing relationships with the actors in the labor market. Finally, the person needs to take action in order to direct her knowledge, skills and attitudes towards a closer match with the needs of the labor market. After doing this, the person can evaluate her own actions, which will lead to new insights, and re-iterate by going back to the introspective phase. The rationale is that performing this PDP process in an ongoing way throughout one's professional life allows a person to build up a career in a more effective way.

In order to make the player learn the above process, we have instantiated the SURM framework to fit the learning needs of VDAB. The statistic categories represent the skills that are needed by employees in the labor market and on which the employee needs to reflect to perform personal introspection. This could be for example "leadership" or "creativity”. The labor market insights are represented by the rank, through the setting of objectives that reflect certain needs of the labor market. An example of such a rank would be "expert leader" or "negotiator". The

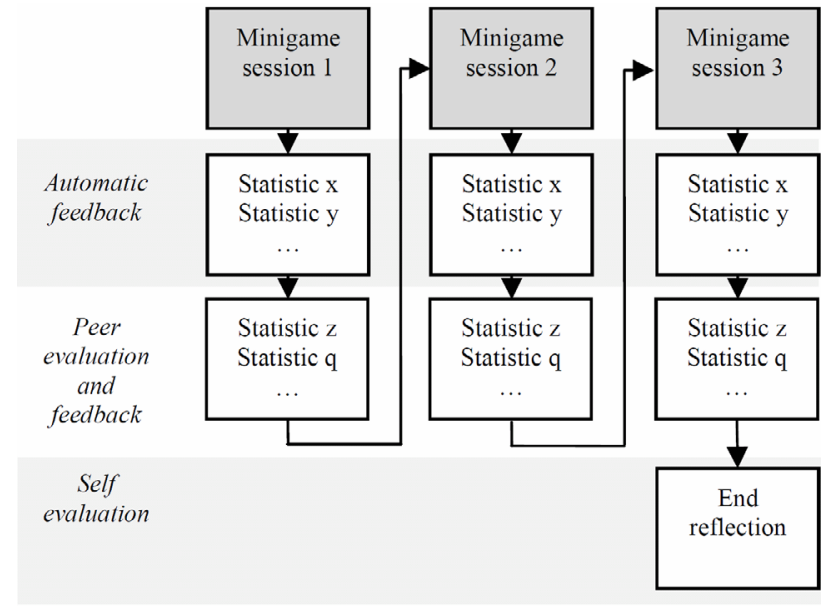

Figure 3. Generic feedback mechanism in the mini-games 
player needs to play the mini-games to be able to improve her skills and achieve a new rank. The unlockables are purely game play oriented and are not necessarily tied to a pedagogical component. They provide objects and capabilities that are relevant within the scope of the labor market, but do not necessary lead to learning. Unlockables alter game mechanics without much expected learning outcomes and are therefore a witness to the dual nature of serious games, which constantly needs to strike a balance between fun and learning [6].

\section{B. Levels of learning}

There are two levels of learning in this demonstrator. At a higher level, the player is made to understand the process of the PDP. In the game, improvement leads to new options, like new games and unlockables. When the player makes the link to real life, he will be made to see that personal actions also lead to new options. For example, that improving his language skills may lead to new career options. The dynamic path in the game shows the player that there are different possibilities to improve on a skill.

At a lower level, each mini-game is designed to familiarize the player with a specific set of skills. The minigames we are currently implementing are discussed next.

\section{The mini-games}

The player enters the virtual world in a general space in which he can access several sources of information and enter rooms to play mini-games. By playing mini-games, players can improve their scores on statistic categories. In order to achieve a goal, the players have to improve their score on certain statistic categories. An example of such a goal would be to "become a charismatic leader". In order to achieve this objective, they would have to reach a certain score on the leadership and communication statistic categories. In order to improve their scores, players undertake actions like playing a mini-game, taking a quiz or watching a video. Interaction between players is a key feature of the mini-games. Feedback is provided through multiple evaluation channels, like automatically generated feedback, peer feedback, coach feedback and selfevaluation.

\section{1) The truth and lies mini-game}

The truth and lies mini-game is an easy-to-play game that can be played by at least three players and consists of three sessions. In each session, each player has to tell a story of one minute about a predefined topic, for example previous jobs or vacation experiences. Before telling the story, the player has to decide and indicate whether the story will be true or false. After a player has told his story, the fellow players must guess whether the story is true or false.

By playing the truth and lies mini-game, the player can increase his scores on the statistic categories "persuasiveness", "Dutch language skills" and "communication". Providing the player with feedback creates a learning outcome. Figure 4 shows the structure of feedback in the mini-game. A player's score on the persuasiveness statistic is automatically calculated based on the assumptions (in this case true or false) made by the fellow players. If the other players guessed the genuineness of a player's story, the story is considered to be persuasive and the player gains points on the persuasiveness statistic category.
In order to obtain a score on the statistic categories "Dutch language skills" and "communication", the fellow players need to rate the performance of the player on a Likert scale with "good, "acceptable" and "point of improvement" as subscales. The scale is formulated positively because positive feedback is considered by VDAB to be more motivating for players to change their behavior. In order to create a safe environment, the consequences of failure are minimized.

In addition to the rating on the Likert scale, a player can write constructive hints on how each fellow player can improve his skills within the mini-game. The player receives the feedback that each fellow player has written for him. When none of the hints are applicable, the player is provided a hint from of a pre-populated database. The player has to indicate which hint he will apply in the next round of the game.

In order to stimulate players to formulate constructive and acceptable feedback, a player can rate the quality of the feedback he received. This provides the player who gave the feedback in the first place with "meta-feedback". The scores that a player receives as meta-feedback from other players are reflected in the "human understanding" statistic category. The user-generated feedback is stored and reviewed by the system administrators. If a usergenerated hint is deemed particularly valuable, it will be stored in the hints database. In this way- a user-generated hints database is created that allows the feedback mechanism to become better as more players have played the game.

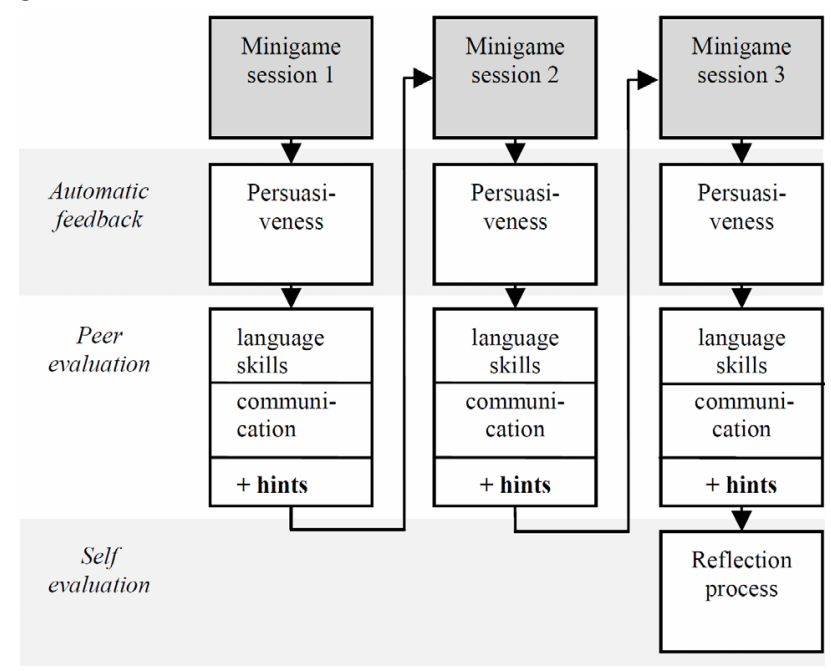

Figure 4. feedback structure of the truth and lies mini-game

At the end of the three sessions, the player should reflect on the process he went through. He can then decide to replay the same game or play a different mini-game.

\section{2) The negotiation mini-game}

The goal of this mini-game is to give the player insight in some basic negotiation mechanics. Negotiation is an important skill in the labor market, making it fit for inclusion in the VDAB demonstrator. Our aim when designing this game was to create a game mechanic that represents a generic negotiation, while still being fun.

In the game, a player is given a set of items he can acquire and a payoff matrix, i.e. a list of objects and associated payoff score. The objects in the list are owned by other players and are to be acquired through negotiation. 


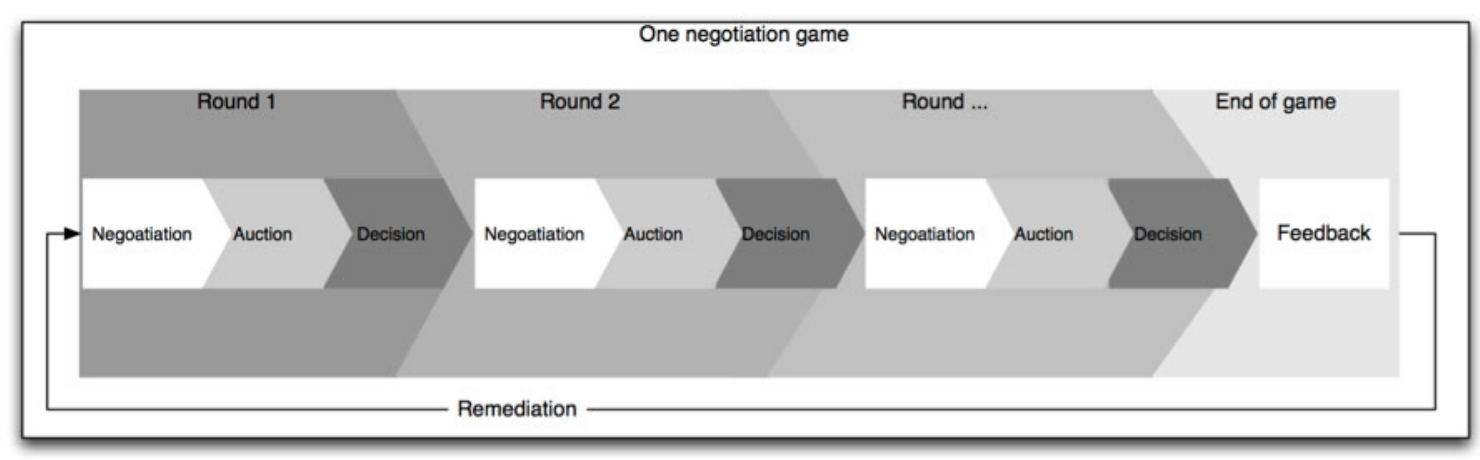

Figure 5. Structure of the negotiation game

One object is always in the list of more than one player, to make sure that there will be competition during the negotiation. The players also get a number of items in their possession and an amount of credits they can use to buy the item during the negotiation.

Figure 5 shows the structure of the negotiation minigame. During each round, an item is selected and offered for sale. The players are first given a period during which they can engage in private negotiations with each other. This negotiation phase allows them to find out how much the other players are interested in the item for sale and to gauge the amount they would be willing to pay for it. In addition, players can make deals with each other. For example, player 1 could tell player 2 that he would be willing to refrain from bidding on object $\mathrm{A}$ if player 2 would do the same when object B is up for sale.

Next is the auction phase, during which each player can place a bid for the item on sale. The players do not see how much each of them bids. During the auction phase, the players can honor the agreements that were made during the negotiation phase, or they can choose not to. This introduces an element of suspense ${ }^{1}$, as players can betray each other. In addition, there is a learning effect pertaining to real life negotiations, where such betrayals can also occur.

In the decision phase, the seller decides which of the players gets the object on sale. The logical move would be to give it to the player who has placed the highest bid, but this is not necessarily the option that the seller will choose. Instead, the seller may decide to sell the item to a player with whom he has made a deal during the negotiation phase. When the decision has been made, the item goes to the buyer and the amount of the bid is deduced from the buyer's account and transferred to the seller.

After all the items have been sold, the game is over and the feedback phase shows the results to the players. The total score of the player is calculated by comparing the items each player has acquired with his payoff list. The player with the highest score is attributed a number of points that are added to his statistic categories. For example, doing well in this mini-game could increase the "negotation" and "communication" statistics. In addition, we are implementing the same peer-evaluation process as in the truth and lies mini-game, depicted in figure 4.

\footnotetext{
1 A similar game mechanic exists in the old boardgame "Diplomacy", of which negotiations are the central part. This game has been popular for more than 50 years due mainly to what we refer to as the "backstabbing mechanic”.
}

\section{TECHNICAL ARCHITECTURE}

The technical architecture, shown in Figure 6, describes how the OSMA-SGE framework is designed to produce a re-usable set of game components that will allow the creation of serious games at a reduced cost.

We have chosen to develop with the Unity3D engine, a 3D game development editor. Based on its ease of use, extendible architecture and relatively low license cost, Unity3D was selected from dozens of editors for 3D games and $3 \mathrm{D}$ graphics as the most suitable editor for the project. The game assets, i.e. the 3D graphical models as well as the sound elements, can easily be imported in the Unity editor to allow re-use. Once the game is created in the editor, it only needs to be compiled to become playable.

In order to lower production costs, we are introducing a back-end which allows non-experts to quickly configure a number of basic variables, like the texts of dialogues with NPC's. In order to allow this, the game communicates with the OSMA-SGE backend, a Drupal-based Content Management System (CMS).

This backend stores the configuration settings of the games on different levels. In addition, it allows for the configuration of a new game context as a collection of existing mini-games for which some prefixed parameters can be easily adjusted. The mini-games in turn consist of a number of configurable components. Since the OSMASGE project focuses on multiplayer interaction, the main emphasis is on the component supporting the communication (text, chat, voip) of the different players in the game.

Besides the re-use of mini-games and components, the presented technological framework has another important advantage. The different game elements can be loaded dynamically while the player is using the game and, as such, updating game content (dialogues, images) does not imply that the game needs to be recompiled.

It is important to note that the game not only retrieves data from the OSMA-SGE backend. Some of the data generated while playing a game (e.g. scores in the games) enrich the player profile and are stored in the CMS. Moreover, the OSMA backend may serve as a proxy to other frameworks, such as learning management systems (LMS), and can pass on relevant data to these systems.

\section{CONCLUSION}

The presented game design and technical framework have been developed based on one case, of the VDAB. To further extend the design and technical framework, we 

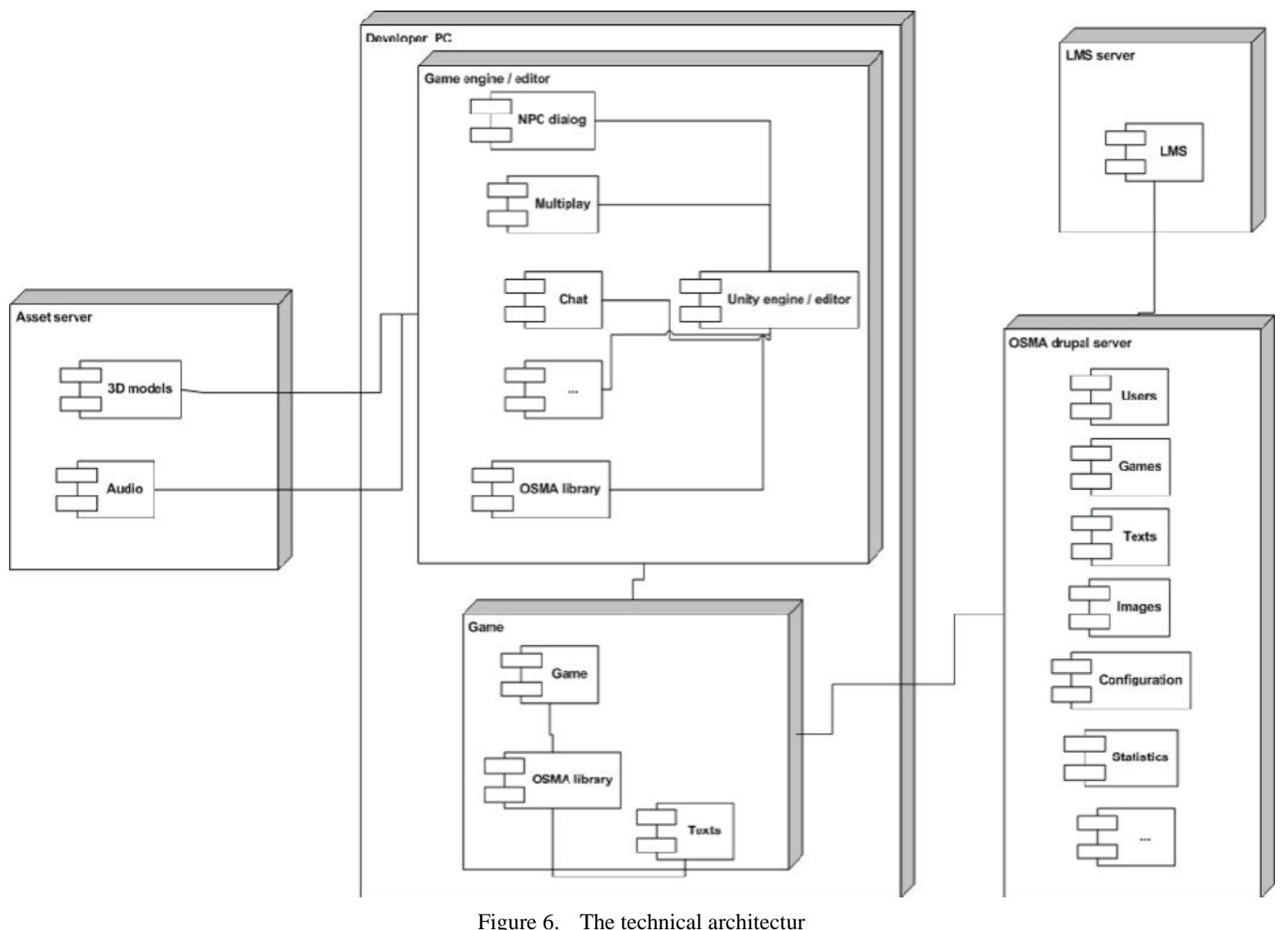

will engage in the development of a second proof-ofconcept, in the sector of cultural heritage.

Still, it is one thing to design a game framework and claim that it will lead to effective and efficient serious games, but another thing to prove that this is really the case. Once the demonstrators have been completed, we will engage in the testing of the games to see if they deliver the expected performance.

Besides the technical and knowledge output of this project, we would like to create a set of "serious game design patterns" that can be used in serious games to facilitate their design. Finding a balance between the fun and educational aspects of a serious game is quite hard and we expect the patterns to facilitate the design. The design patterns will represent best practices in resolving salient multiplayer serious game design problems.

Multiplayer serious games will be an interesting are of further research in the serious games domain. It seems that almost no projects are being conducted under this label. In our recent survey of the serious games field, we have encountered no multiplayer serious games, besides America's Army. Still, America's Army is a multiplayer firstperson shooter in which communication between players is an afterthought rather than a core element of the game.

We find that multiplayer serious game genre is well suited for the combined application of constructivist, experiental and zone of proximal development learning theories. However, the way in which these theories can be applied in multiplayer serious games needs further investigation, as no conceptual framework exists to date that can guide the development of and theoretical reasoning on this type of game.
We have proposed to create a game framework called SURM that is based on MMRPG's. The rational for adopting this framework is that its constituents have proven their worth to create games that are sustainably enjoyable. In addition we have proposed, in the form of the VDAB demonstrator, ways in which these elements can be applied to create a game that is both educational and entertaining.

\section{ACKNOWLEDGMENT}

OSMA-SGE is an acronym for Open Source Multiplayer Adventure- Serious Game Engine. The project started in October 2009 and will be finished September 2011. The project is funded by the Flemish IWT-Tetra research fund and the companies and organizations in the steering committee. Our thanks to all these organizations for offering valuable help and input.

More information can be found on the project website http://www.phl.be/osma.

\section{REFERENCES}

[1] Torrente,J., Moreno-Ger,P., Fernández-Manjón,B., \& del Blanco, A. Game-Like Simulations for Online Adaptive Learning: A Case Study. Presented at Edutainment 2009 Fourth International Conference on ELearning and Games, Banff, Canada.

[2] U. Ritterfled, M. Cody, and P. Vorderer, "Serious games: explication of an oxymoron - Introduction,” Serious games - Mechanisms and effects, London and New York: 2009, pp. 4-9.

[3] K. Salen and E. Zimmerman, Rules of play, Cambridge, Massachusetts: The MIT Press, 2004.

[4] A. Yusoff, L. Crowder, and G. Wills, “A conceptual framework for serious games,” Riga, Latvia: 2009.

[5] R.J. Nadolski, H.G.K. Hummel, H.J. van den Brink, R.E. Hoefakker, A. Slootmaker, H.J. Kurvers, and J. Storm, "EMERGO: A 
methodology and toolkit for developing serious games in higher education,” Simulation Gaming, vol. 39, 2008, pp. 338-352. doi:10.1177/1046878108319278

[6] R. Ratan and U. Ritterfeld, "Classifying serious games” in Serious games - Mechanisms and effects, New York and London, Routledge, 2009, pp. 10-24.

[7] T. Newby, D. Stepich, J. Lehman et al., "Designing instruction, integrating computers, and using media”, in Instructional technology for teaching and learning, NJ, Prentice Hall, 1996.

[8] C. Reigeluth, Instructional-Design Theories and Models Volume II: A New Paradigm of Instructional Theory, Mahwah, NJ, Lawrence Erlbaum Assoc, 1999.

[9] L. Uden, L. and C. Beaumont, "Technology and problem-based learning”, London, United Kingdom, Information Science Publishing, 2006

[10] D. Phillips, "Constructivism in Education: Opinions and Second Opinions on Controversial Issues”, Chicago, Chicago University Press, 2000.

[11] P. Kirschner, J. Sweller and R. Clark, "Why minimal guidance during instruction does not work: An analysis of the failure of constructivist, discovery, problem-based, experiential, and inquiry-based teaching”, Educational Psychologist, 2006, pp 75-86. doi:10.1207/s15326985ep4102_ 1

[12] K. Kiili, "Digital game-based learning: Towards an experiential gaming model” in Elsevier: Internet and Higher Education 8, 2005, pp. 13-24. doi:10.1016/j.iheduc.2004.12.001

[13] S. Holland, Remote relationships in a small world, New York, Peter Lang Publishing, 2007.

[14] D. Kolb, "Experiential Learning: experience as the source of learning and development”, New Jersey, Prentice-Hall, 1984.

[15] Thomson, M. experience-based learning - guide to facilitating effective experiential learning activities, 2008, Retrieved from http://www.businessballs.com/experiential_learning.htm
[16] N. Falchikov, "Peer feedback marking - developing peer assessment” in Innovations in Education \& Training International, 1995, pp 175-187.

[17] E. Redish and M. Vicentini, "Research on physics education" in International School of Physics series Volume 156, 2004.

[18] L. Vygotsky, Mind and society: The development of higher psychological processes, Cambridge, University Press, 1978.

\section{AUTHORS}

T. Coenen was with the Vrije Universiteit Brussel, Brussels, Belgium and is now with the PHL University College, Hasselt, Belgium and the Interdisciplinary Institute for Broadband Technology, Gent, Belgium (e-mail: tanguy.coenen@gmail.com).

E. Cloosen, was with Universiteit Antwerpen, Antwerp, Belgium and is now with the PHL University College, Hasselt, (e-mail: evelyn.clooosen@gmail.com).

V. Van der Sluys is Play\&Game research coordinator at the PHL University College, Hasselt, Belgium and the KHLim - Media \& Design Academy, Genk, Belgium (email: veerle.vandersluys@phl.be)

F. Smolders, was with Universiteit Hasselt, Diepenbeek, Belgium and is now with the PHL University College, Hasselt, (e-mail: frederik.smolders@phl.be).

The project is funded by the Flemish IWT-Tetra research fund and the companies and organizations in the steering committee.

This paper is an extended version of a presentation given during the "Creative Learning with Serious Games" workshop during the "Fun and Games 2010" conference in Leuwen on 15 September 2010, and was supported by the e-VITA European Life Experiences”, project $\mathrm{nr}$ 143526-LLP-1-2008-1-IT-KA3-KA3MP.

Submitted October $31^{\text {st }}$, 2010. Published as resubmitted by the authors November $11^{\text {th }}, 2010$. 